\title{
Survey on the Structure of city Wall Comprehensive Landscape System Based on the Principle of "Authenticity" and "Integrity"-Take the Xi'an City Wall as an Example
}

\author{
Yifei Wang \\ School of Economic Management, Xi'an Fanyi University, Xi'an, Shaanxi, 710105, China
}

Keywords: Authenticity, Integrity; Xi'an city wall, Context integration, City wall landscape system

\begin{abstract}
On the basis of fully investigation on current theoretical research result of cultural heritage protection duality principle and context analysis problem, and fully understand the duality principle of "authenticity" and "integrity" on cultural heritage protection, the paper analyzes the current situation of the protection and utilization of Xi'an city wall, points out problems exist in Xi'an city wall landscape belt, such as partition of internal and external visual landscape, lack of historical environment, context had not been fully merged in the landscape design and construction and so on. Secondly, take "context integration" as entry point, explain the construction concept of "city landscape system” from time and space; and make further logical argumentation by using the duality principle of "authenticity" and "integrity", points out that the city wall context integration emphasized the normally neglected integrity of "culture concept", thus truly realized the combining application of duality principle.
\end{abstract}

\section{Introduction}

The duality principle of "authenticity and integrity" is the fundamental guarantee to express the world heritage inheritance of human civilization and to reflect the evolution of nature. The concept of "authenticity" first appeared in Venice Charter,1964, explanation about it was firstly found in The world heritage convention implementation guidelines (for short Guidelines, 1995), more detailed explanation was found in Nara Document, 1994. For the principle of "authenticity and integrity", Zhang Chengyu and Xie Ninggao once made a comprehensive explanation and analysis, and pointed out the limitation of international documents, that is "authenticity" and "integrity" are entirely separated, the authenticity principle was for cultural heritage; integrity was for natural heritage. The author proposes to fully understand two principles. "No matter cultural heritage or natural heritage, evaluation, estimation and protection on them normally need to involve both authenticity and integrity."In other words, natural heritage also exists authenticity problems; while "integrity" is also suitable for cultural heritage.

This duality principle is not only suitable for world heritage, it also has important guiding role and realistic significance on the protection of normal historic human heritages. Comprehensive understanding and application of the spirit and essential of the duality principle can help people to better protect cultural heritages and inherit local contexts. The word "context" is translated from English, its original meaning is "(word, words, sentences in the article)context; (things) environment and background". In the middle 90s, Chen Chuankang once made a classical definition for "context”: the so-called "context" is the geographical background of the tourist area, including natural environment features like geology, landform, climate, soil and hydrology; and also including human geographical features like local history, society, economy and culture. Li Leilei (1998) thought context is a kind of "four dimensional combination of comprehensive, regionally natural geographical basis, historical cultural tradition and social psychological accumulation”.

With the progress of tourist development practices, the concept of context is gradually more and more clear and perfect, it is not a single concept any more, but is combined with the historical human heritage protection, plan, development and image planning of tourist areas, even with the planning and construction of the whole city. 


\section{Current situation analysis of Xi’an city landscape}

For safety, city wall once was necessary for ancient city and towns. city wall not only made a clear definition for ancient cities from space, but also becomes an important space for developing around city park, providing recreation for citizens and tourist sightseeing in domestic. Drawing -1 shows parts of current reserved city walls in China.

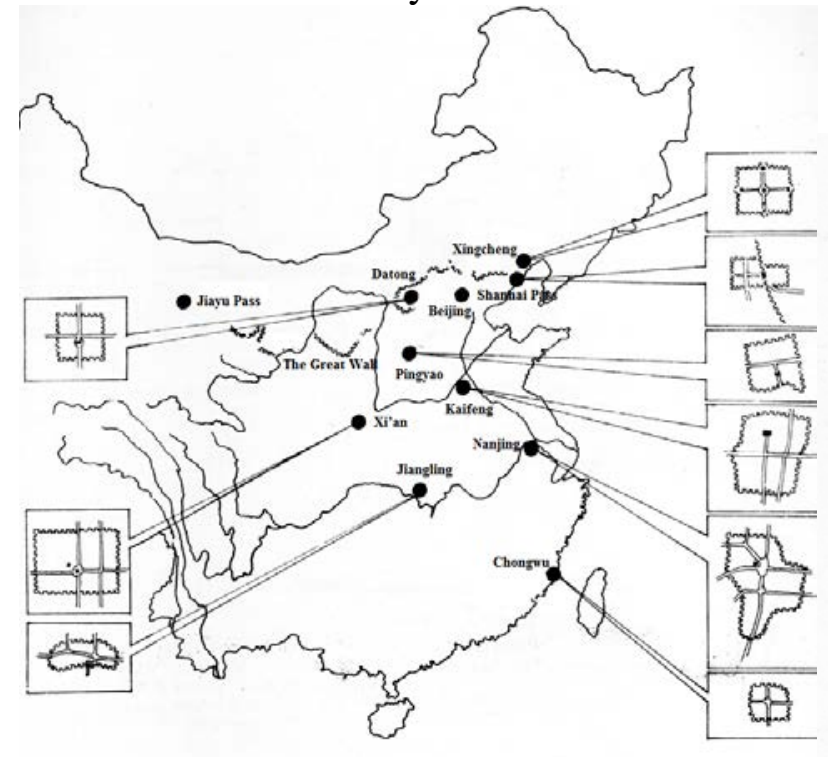

Fig. 1. Distribution of part of ancient city walls in China

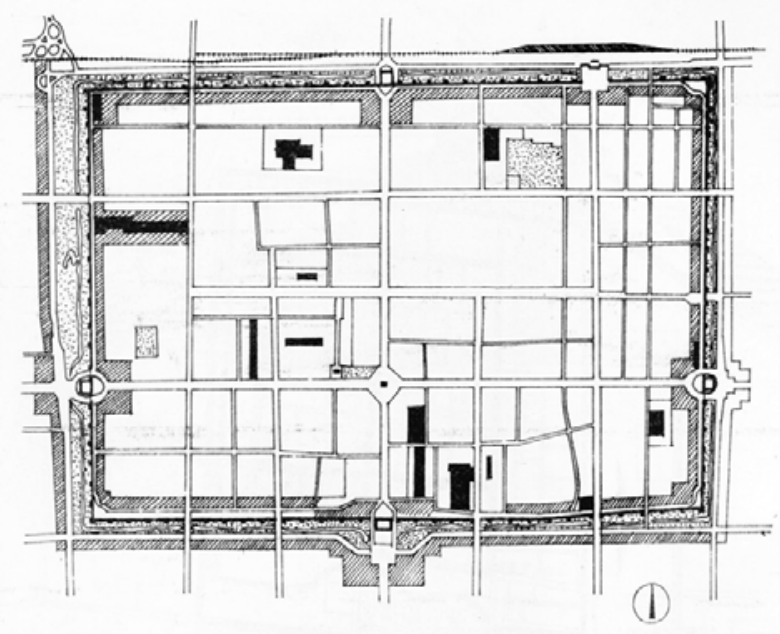

Fig. 2. The ancient City Wall of Xi'an

With the length of 14 kilometers and area of 11.5 square kilometers, the current existing Xi'an city wall (Drawing-2) is the remain that built with black bricks in the second year of Longqing, Ming dynasty (1568) and repaired in large-scale in the period of Qianlong, Qing dynasty, its style is a continue of Han and Tang dynasty. Since 1983, Shanxi provincial and Xi'an municipal people's government have made a large-scale repair on the Xi'an ancient city wall. At present, it has been formed the city wall landscape with city, river, forest, and road together, the inner side of the city wall is the around-city road, the outside is the green leisure belt around the city, now it already becomes a big tourism landscape. Through field visit, the author found that though the protection measures started in 1983 were pretty complete but after over 30 years, the current situation of the protection and utilization of city wall still exists following mentioned problems.

First of all, the city wall landscape belt exists inside and outside partition and lacks of environment echo, thus affected the integrity of the landscape.

Complete Xi'an city landscape belt should be consist of city wall, outside around city forest green leisure landscape belt and inner side around city road human cultural landscape belt, and be felt by people and forms the whole cognition of city wall landscape. While, two landscape systems inside and out side the city wall are separated, these two systems have obvious differences on thematic function, spatial distribution, ecological environment and cultural atmosphere, architectural style, distribution principle and color matching. The city wall actually becomes a isolated culture monomer, awkwardly lies in the modern urban life for lack of environment echo. All these weakens the authenticity and integrity of this historical heritage, city wall.

Secondly, lacks of further cognition and excavation of city wall context.

While Xi'an city wall was built in Ming dynasty, it continued the style of Han and Tang dynasty and culture accumulation, thus cohesion in the city wall is a comprehensive culture system that across multiple dynasties, this system together with other historical cultural heritages, traditional folk custom and social psychological accumulation of Xi'an to form the special context of Xi'an. The final purpose of the city wall protection is to continue this kind of context. While at present, the cognition of protection work on the city wall context, even the context of Xi'an is obscure. On one hand, what kinds of material and immaterial historical relics are unchanged when the original architectural characters and functions changed from the initial imperial city of Tang dynasty with thousand years' 
historical changes? What kinds of changes have the throughout cultural core experienced and what kinds of relative stable characters have been kept and will be carried down continue? On the other hand, what are the differences among Xi'an city wall, Nanjing city wall, Pingyao city wall, Suzhou city wall and original Beijing city wall? What are the difference of their inner accumulated cultural features? All these need a further research of the theory circle.

At last, did not fully merge context into the design and construction of landscape, thus formed the partition of invisible culture and visual landscape.

Once cultural entities like cultural relics lost context, it lost its soul and would become isolated, withered and no connotation; meanwhile, if the context lost the support of cultural relics, it lost entity and soil thus become unviewable (Zheng Xiangmin, 2004). Even there is a well grasping of city wall context, but cannot express it with entity to strengthen and emphasize, thus context will be gradually "withered".

According to the questionnaire survey that collected from the city wall site by the author in 2014 (Drawing-3), about $17.6 \%$ of the domestic tourists who take part in the survey thought it was "very antique" , while $76.5 \%$ thought it is "not antique, but too modern"; $52.6 \%$ the overseas tourists thought it is "antique enough", 42.1\% thought "modern rather than antique", and 5.3\% thought “completely modern”.
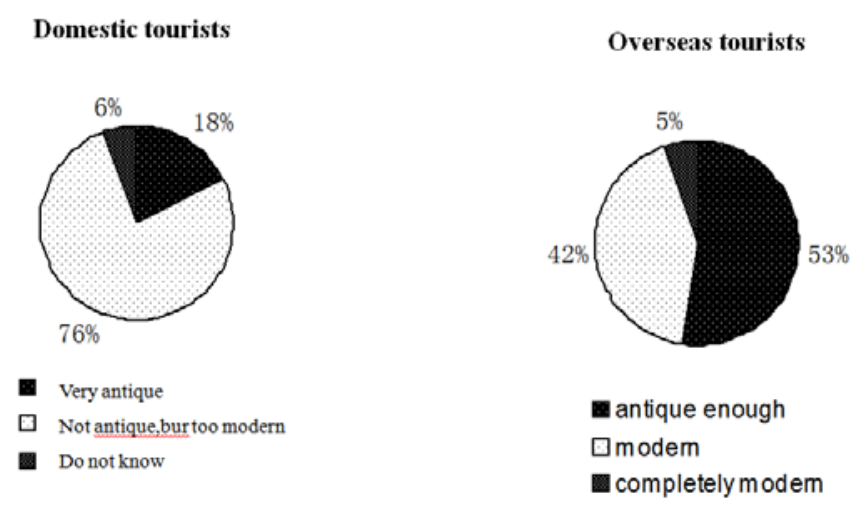

Domestic tourists

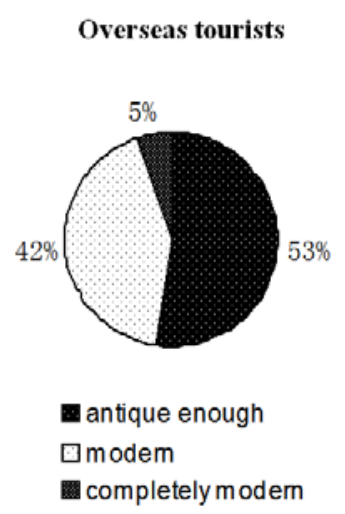

Fig. 3. Pie chart of the survey results

a. Answer for "Does the landscape around the city wall antique or not?"

b. Answer for "Can you feel the shock of Chinese ancient historical culture when you stand on the city wall?”

For the same batch of questionnaire survey (Drawing-3:b), for the question "Can you feel the shock of Chinese ancient historical culture when you stand on the city wall?" 36.8\% of the domestic tourists chose "Yes", while 57.9\% chose "No"; $64.7 \%$ of the overseas tourists showed positive answer, and $29.4 \%$ showed negative attitude. 


\section{“Landscape context integration” form the angles of time and space}

For above mentioned problems existing in the current situation of the protection and utilization of city walls, traditional "monomer protection view" cannot inherit context effectively, but will cause the interruption of context. Cultural relics' environment is soil for its growth, protect cultural entities while neglect to protect its environment also a break to context, especially for important ancient sites and historical streets that strongly dependent on environment (Zheng Xiangmin, 2004). This view established a theoretical basis for the propose of the concept of "context integration". Thus the author thought it is necessary to propose the concept of "city wall comprehensive landscape system", interpret the construction of Xi'an city wall landscape system from the two dimensional angles of time and space.

Time axis. Time axis is set the historical development of city wall, Xi'an, even the whole China as mainline, starts form the origin of history, throughout all previous dynasties and will continue to extend to the future. From the rudiment of "city" in the Zhou dynasty to the city development in Han dynasty, city wall was addressing and molding formally in Sui and tang dynasties, and formed the superposition of multiple functions and cultures and left abundant history information based on the construction, continuing use, renovation and repair throughout the Five Dynasties, Song Dynasty, Yuan dynastic, Ming dynasty and Qing dynasty. It not only reflects culture of a special dynasty, but the combination of Chinese ancient cultures that with four cultures of Zhou dynasty, Qin dynasty, Han dynasty and Tang dynasty, including visible and invisible historical factors and cultural information, these factors have already formed a stable relationship, coexist with each other and made up an organic cultural system.

From the aspect of time axis, the key is to make the cultural system fully expressed in the city wall to make the Chinese ancient cultures that with cultures of Zhou dynasty, Qin dynasty, Han dynasty and Tang dynasty as representative culture to be penetrated, coordinated and unified. Under the premise of not break the inherent history, arts and scientific values, maximum recover the real original appearance of history and the understanding of four cultures, make it express to people unified and real, thus to break people's unilateral cognition that the city wall was just the outcome of Ming dynasty, to realize the complete expression and integration of the longitudinal through context and reappear the image of Han dynasty and Tang dynasty and the style of Ming dynasty and Qing dynasty.

Space axis. Xi'an city wall landscape system should be a comprehensive landscape system that consists of the city wall, around city green forestry belt, city moat, around city road and inner circumferential district of $\mathrm{Xi}$ an City Wall. They are not only a complete entirety on the spatial structure, even more on the cultural concept. The construction of space axis takes the city wall architectural entity as center point to make comprehensive treatment and systematic protection on the wall, forest, river, road and lane, gradually recover historical human landscape system from the aspect of implements, behaviors, customs and cultural concepts.

Firstly, break the partition of the landscape and culture of the inside and outside of the city walls. On one hand, as the humanistic resources of the four directions along the city wall as main basis to make the landscape theme of the around city forest close to the theme of Shuncheng lane, it is not just the leisure place for citizens but also should be part of the city wall culture and to extend city wall context. On the other hand, for material and immaterial heritages of the Shuncheng lane district, such as the ancient architecture, traditional residence, religious temples, painting and calligraphy and lane cultures, based on its original style and traditional spatial framework, and maintain according to the principle of "remain old as before" to form the integral cultural atmosphere. Thus to realize the coordination and unification of the visual landscape and cultural connotation of inside and outside of the city wall.

Secondly, conduct the "visual corridor construction" around the city wall, maintain the historical authenticity of the city wall and the broad environment around it. "Visual corridor" means to control the height of modern architectures to stand out the ancient architectures within the sight range, and guarantee the completeness of space composition and the view borrowing need in a certain scope (Sun Wenchang, 2001) . The important way to solve visual corridor is to restrict the height of 
surrounding architectures. Except height controlling, the construction projects in the inner district of the ancient city wall should comply with the planing requirements of its protection areas. The new build, rebuild and extended architectures and structures, its volume, molding and color should reflect the style and features of traditional architectures, remain old as before, keep the original appearance.

Intersection of the two axis. Through the construction of two-dimension angle of view of time axis and space axis reaches the intersection point of mutual balance, that is the target of the application and expression of context integration thoughts in the city wall landscape system: the green landscape out of the city wall and the humanistic landscape inside the city wall should be unified in the integrated context, that is the five factors of wall, forest, river, road and lane should unified in the integrate context of the city wall, final to form the visual coordination and cultural unification; inside and outside affiliated and multiple functions Xi'an city wall comprehensive landscape system (Drawing-4).

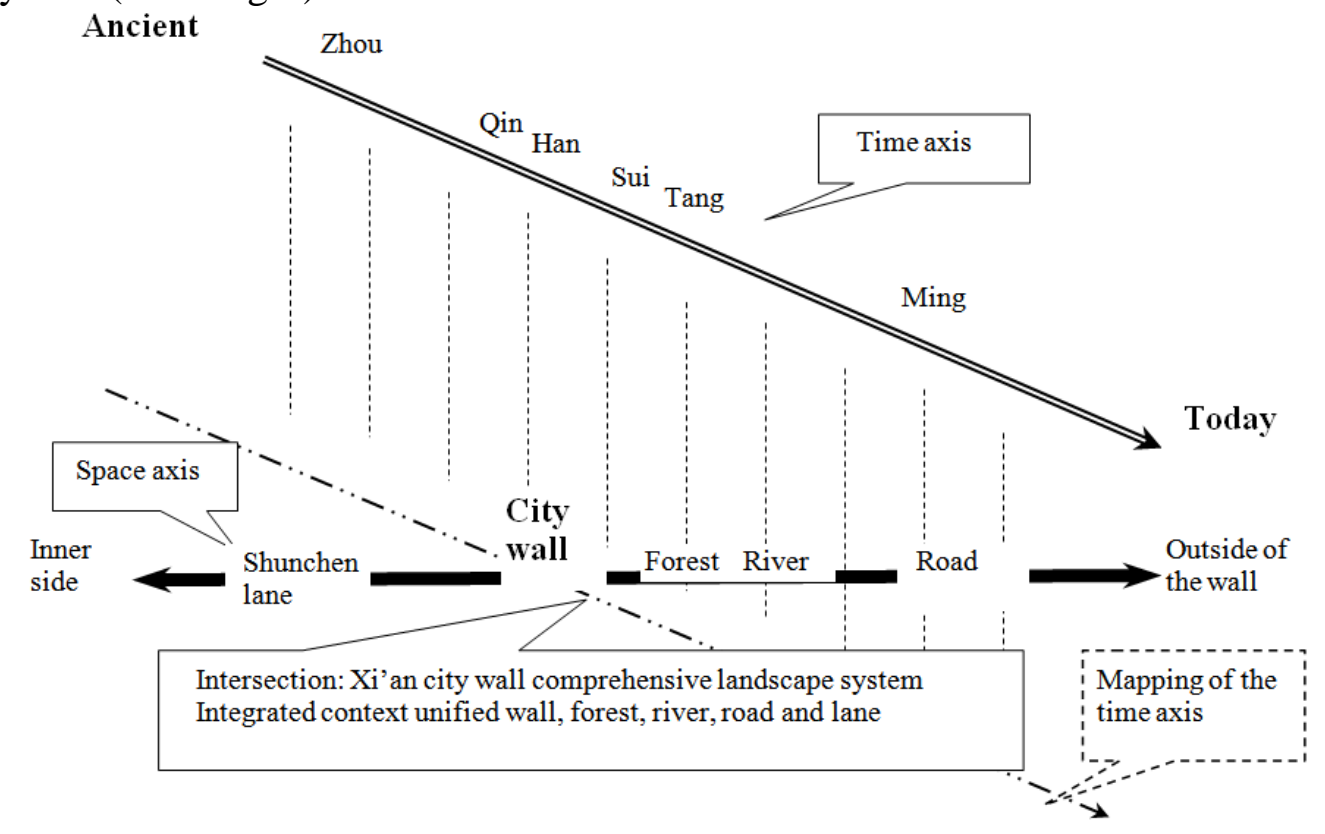

Fig. 4. The Synthetic Landscape System(SLS) of Xi'an City Wall

Protection of cultural heritage and historical sites is to appreciate cultural heritage and be enlightened by humanistic cultural wealth, maximum improve human's living state and mental state, to make cultural heritages not just be a pure memorial of last, but the extend ability for traditional cultures, to make traditional culture really merge into modern life and be inherited to realize the real renaissance of traditional civilizations (Wu Xiaojuan, 2004). Thus the real and most radical purpose of the application of duality principle is to make the cultural heritages can be inherited and used sustainably, thus to express the long-term humanistic sensibility and cultural caring of modern world to the future on a further cultural layer.

\section{References}

[1] Nara Document. Nara Conference on Authenticity in Relation to the World Heritage Convention. Tokyo UNESCO-World Heritage Center/ Agency for Cultural Affairs/ ICCROM/ ICOMOS, 1994.

[2] Sun Wenchang. Modern Tourism Development the 2nd edition. Qingdao: Qingdao Press, 2001:219.

[3] Zhang Chengyu. “Authenticity” and "Integrity” are Basic Principles for Heritage Protection. Protection and Operation of Cultural Heritage--Progress of Chinese Practice and Theory the 1st edition. Beijing: Social Sciences Academic Press, 2003:76-91. 
[4] Bao Zhanbin. Discussion on the Functions and Values of Historical and Cultural heritage. Journal of Shaoxing University, 2002:92-95.

[5] Bao Zhanbin, Cao Hui. Countermeasures on the Protection and Development of Historical and Cultural heritages. Journal of Ningbo University (Humanities edition), 2002:85-88

[6] Wu Xiaojuan. Research on the Authenticity Dilemma of Cultural Heritage Tourism. Thinking, 2004:82-87.

[7] Zhang Chengyu. Analysis and Extension of Two Important Concepts in the World Heritage Convention--Discussion on the "Authenticity" and "Integrity” of World Heritage. Journal of Beijing University (JCR Science Edition),2004:129-138.

[8] Zhang Chengyu, Xie Ninggao. Principle of “Authenticity” and "Integrity” and World Heritage Protection. Journal of Beijing University (philosophy and social science edition), 2003:62-68.

[9] Zheng Xiangmin, Lin Meizhen. Discussion on the Cultural Relics Protection and the Context Inheritance and Suspension--and Discussion on Some Points of View in the Tourism Tribune. Tourism Tribune, 2004:25-29 